\title{
ON COSMIC-RAY EXPOSURE AGES OF TERRESTRIAL ROCKS: A SUGGESTION
}

\section{DEVENDRA LAL}

Scripps Institution of Oceanography, Geosciences Research Division, La Jolla, California 92093-0220 USA

\begin{abstract}
An important recent development in the field of geomorphology has been the application of in-situ cosmic-rayproduced nuclides to obtain model erosion rates and surface exposure ages. These concepts emerged some four decades ago in studies of cosmogenic nuclides in meteorites, but cannot generally be used analogously for terrestrial rocks. The differences in the two cases are outlined. For the case of steady-state erosional histories, the terrestrial surface exposure ages depend on the half-life of the radionuclide studied. A suggestion is made for presenting the surface exposure ages, which allows a clear definition of the meaning of the estimated exposure ages. In the case of a discrete exposure history, the meaning of "exposure age" - which should more appropriately be called "event age"-is however quite unambiguous.
\end{abstract}

\section{DISCUSSION AND SUGGESTION}

Nuclear methods have been used to determine a variety of "ages", e.g., the time elapsed since a volcanic rock cooled, and the duration of cosmic-ray exposure of a meteorite in space between the time it was ejected from a planetary body and its capture by the Earth (Geiss et al. 1966; Marti and Graf 1992). Four simple examples of discrete events which can be fairly well modeled with just a few degrees of freedom are listed in Table 1 . In these cases, the model "ages" do not depend sensitively on several parameters. The most unambiguous definition is in the case of a volcanic eruption, where the clock is reset to zero (i.e., when the rock cools down). The cooling event refers to the closure of a mineral in the whole rock, and the "date" is valid for the whole rock or a part of it. Application of radionuclides to problems of mixing and transport is an example of a complex model, where the result can be very sensitive to both the model and the parameters. Cosmic-ray exposure ages of meteorites and terrestrial objects are cases of intermediate complexity, as qualified below.

In recent years, with the development of accelerator mass spectrometry (AMS), it has become possible to measure several cosmogenic radionuclides, of half lives $10^{2}-10^{6} \mathrm{yr}$, in terrestrial rocks for determining model rock exposure ages analogous to the case of exposure ages of meteorites (Nishiizumi et al. 1986, 1993; Phillips et al. 1986; Lal 1988, 1991; Brown et al. 1991; Brook et al. 1993). Recent improvements in the measurements of noble gases have also made it possible to measure cosmogenic ${ }^{3} \mathrm{He}$ and ${ }^{21} \mathrm{Ne}$ in surficial rocks (see the review by Cerling and Craig 1994). As a result of these developments, a number of papers have appeared giving cosmic-ray surface exposure ages of rocks (Kurz et al. 1990; Nishiizumi et al. 1993; Cerling and Craig 1994; Gosse et al. 1995; Bierman et al. 1995).

A central problem in determining the exposure age of a sample is that the geometry of the "sample" continually changes during its exposure to cosmic rays, due to mass wastage by erosion or fragmentation. So, in the strictest sense, it is not meaningful to assign an "exposure age" to a sample, because the object continually assumes a different identity as the cosmic-ray irradiation proceeds. If, however, the cosmic-ray effect being studied is not too sensitive to the range of changes in the geometry and shape of the object, the model exposure age should be similar in magnitude to the case in which the object was immutable during exposure. The situation for in-situ cosmogenic nuclides in terrestrial rocks is quite different from that in meteorites, primarily due to two factors: differences in the erosion rates, and in the hardness of the energy spectrum of protons and neutrons in the $\mathrm{MeV}-\mathrm{GeV}$ energy region, responsible for production of the nuclides (see Lal 1988). 
TABLE 1. Model Dependence of Exposure Ages for Different Rock Histories

\begin{tabular}{|c|c|c|c|c|}
\hline & Event history & Isotopic marker(s) & $\begin{array}{l}\text { Important } \\
\text { constraints in } \\
\text { modeling }\end{array}$ & $\begin{array}{l}\text { Remarks on time } \\
\text { interval and time } \\
\text { history }\end{array}$ \\
\hline I. & $\begin{array}{l}\text { Cooling of a volca- } \\
\text { nic rock }\end{array}$ & $\begin{array}{l}\text { Radioactive decay } \\
\text { and accumulation of } \\
\text { daughter nuclides }\end{array}$ & $\begin{array}{l}\text { Validity of the } \\
\text { closed-system } \\
\text { model* }\end{array}$ & $\begin{array}{l}\text { Precisely defined for } \\
\text { a closed system; } t=0 \\
\text { at emplacement. }\end{array}$ \\
\hline II. & $\begin{array}{l}\text { Ejection of a rock } \\
\text { from an asteroid or } \\
\text { a planetary surface }\end{array}$ & $\begin{array}{l}\text { In-situ nuclide pro- } \\
\text { duction and accumu- } \\
\text { lation of stable and } \\
\text { radionuclides }\end{array}$ & $\begin{array}{l}\text { Post-ejection col- } \\
\text { lisional history }\end{array}$ & $\begin{array}{l}\text { Fairly well defined } \\
\text { for moderate colli- } \\
\text { sional histories; ef- } \\
\text { fects of erosion in } \\
\text { spaces are generally } \\
\text { inappreciable. }\end{array}$ \\
\hline III. & $\begin{array}{l}\text { Episodic surface } \\
\text { exposure of a deep- } \\
\text { seated rock due, } \\
\text { e.g., to glacial ero- } \\
\text { sion or a volcanic } \\
\text { event } \dagger\end{array}$ & $\begin{array}{l}\text { In-situ nuclide pro- } \\
\text { duction and accumu- } \\
\text { lation of stable and } \\
\text { radionuclides }\end{array}$ & $\begin{array}{l}\text { Post-event expo- } \\
\text { sure erosion/ } \\
\text { burial history }\end{array}$ & $\begin{array}{l}\text { Accumulation of nu- } \\
\text { clides is sensitively } \\
\text { dependent on the } \\
\text { post-episodic erosion/ } \\
\text { burial history. Event- } \\
\text { ages are severely } \\
\text { model dependent, ex- } \\
\text { cept maybe in the case } \\
\text { of very recent events! }\end{array}$ \\
\hline IV. & $\begin{array}{l}\text { Continuous long- } \\
\text { term (steady- } \\
\text { state!) weathering } \\
\text { and erosion of a } \\
\text { rock surface }\end{array}$ & $\begin{array}{l}\text { In-situ nuclide pro- } \\
\text { duction and accumu- } \\
\text { lation of stable and } \\
\text { radionuclides }\end{array}$ & $\begin{array}{l}\text { Recognition of } \\
\text { important events } \\
\text { during the (con- } \\
\text { tinuous) ero- } \\
\text { sional history of } \\
\text { the rock. }\end{array}$ & $\begin{array}{l}\text { A special case of III. } \\
\text { Exposure ages may be } \\
\text { severely model de- } \\
\text { pendent (see text). }\end{array}$ \\
\hline
\end{tabular}

*Note: This is a requirement in all isotope models.

$\dagger$ Frequently information on the exposure history of a sample is insufficient to distinguish between Cases III and IV. Even for a volcanic event, Case III often resembles Case IV.

In the case of meteorites, the maximum variation in the nuclide production rates in typical meteoritic bodies of $20-50 \mathrm{~cm}$ radius exposed in space is $<2 \times$, and the micro-meteorite induced erosion rate is $<<1-5 \mathrm{~cm}$ in periods on the order of 10-20 myr. Thus, the example of cosmic-ray irradiation of meteorites is one where one can meaningfully speak of the exposure age of the whole object even though it may be undergoing mass wastage due to erosion, since small changes in meteorite size/ shape do not significantly affect the nuclide production rate, and hence the model age.

For completeness, it is mentioned that for obtaining meteorite exposure ages, one deploys nuclides produced by the nucleonic component of cosmic radiation, which shows a transition in the first 100 $\mathrm{g} \mathrm{cm}^{-2}$, whereby the average nuclide production rates inside an object of 30-50 $\mathrm{cm}$ do not change much with depth (Bhattacharya et al. 1980; Marti and Graf 1992; Reedy 1981). Without going into detail, it may be noted that several methods are applicable for extraterrestrial samples that allow fairly accurate determination of the nuclide production rate during the object's exposure (cf. Marti and Graf 1992). If, however, one measured the track densities in meteoritic/lunar silicate crystals due to multiply charged nuclei, one would obtain a result that is depth sensitive on scales of microns 
to millimeters, depending on the nature of the radiation (solar or galactic) responsible for the tracks (Bhattacharya et al. 1973). In fact, several different exposure ages have been deduced for lunar samples, e.g., the sun-tan and sub-mm exposure ages ( $\mathrm{Lal} 1972)$.

In the case of terrestrial rocks the sample studied sometimes bears little resemblance to its form and substance during most of its cosmic-ray exposure history. Both erosion and the nuclear energy spectrum make "exposure age" models sensitive to the parameters used, as discussed below.

Table 1 shows the isotopic markers, and constraints in their application, for determining model exposure ages for a few commonly investigated cases of interest in planetary science. The simpler Cases I and II in Table 1, namely the time of emplacement at surface of an igneous rock (I) and the cosmic-ray exposure ages of meteorites (II), have already been considered above. The cases of exposure ages of terrestrial rocks, for both discrete and continuous exposures (Cases III and IV), will now be discussed.

In the case of terrestrial surficial processes, several simple exposure models have been considered recently ( $\mathrm{Lal} \mathrm{1991)} \mathrm{for} \mathrm{the} \mathrm{nuclides} \mathrm{produced} \mathrm{by} \mathrm{the} \mathrm{nucleonic} \mathrm{component,} \mathrm{for} \mathrm{which} \mathrm{the} \mathrm{absorption}$ mean free path, $(1 / \mu)$, is on the order of $160 \mathrm{~g} \mathrm{~cm}^{-2}, c a .50-60 \mathrm{~cm}$ in typical rocks (Lal 1988). The nucleonic component is primarily composed of neutrons, with most of the flux lying below $500 \mathrm{MeV}$. The radiation is fairly soft in energy and also fairly directional ( $<1 \pi$ geometry), which should be contrasted with the much harder spectrum and (3-4) $\pi$ geometry in the case of meteorites (cf. Lal 1988). For the case of terrestrial rocks, assuming a constant erosion rate, the simplest exposure history would be irradiation of a rock surface for $T$ years with zero initial nuclide concentration (Lal 1991)

$$
\mathrm{N}(\mathrm{T}, \lambda)=\frac{\mathrm{P}_{0}}{\lambda+\mu \rho \varepsilon}\left[1-\mathrm{e}^{-(\lambda+\mu \rho \varepsilon) \mathrm{T}}\right] .
$$

where $N(T, \lambda)$ is the resulting nuclide concentration at the surface after irradiation for $T$ years, $\lambda$ is the disintegration constant of the nuclide $(=1 / \tau$, where $\tau$ is the mean life of the nuclide), $\mu$, as defined earlier, is the inverse of the mean cosmic-ray nucleon absorption coefficient $\left(\mathrm{cm}^{2} \mathrm{~g}^{-1}\right), \rho$ is the rock density $\left(\mathrm{g} \mathrm{cm}^{-3}\right), \varepsilon$ is the erosion rate $\left(\mathrm{cm} \mathrm{yr}^{-1}\right)$, and $\mathrm{P}_{0}$ is the cosmogenic in-situ nuclide production rate in the rock at the surface. Equation (1) holds for Case III in Table 1, for uniform erosion rate.

In steady state, the surface radionuclide concentration, $\mathrm{N}_{\mathrm{ss}}$, attains an equilibrium value

$$
\mathrm{N}_{\mathrm{ss}} \text { (radionuclide) }=\frac{\mathrm{P}_{0}}{\lambda+\mu \rho \varepsilon}
$$

in the exposed rock surface after irradiation for time, $\mathrm{T} \gg 1 /(\lambda+\mu \rho \varepsilon)$, with $\mathrm{N}_{\mathrm{ss}}$ being a function of radionuclide half-life. Note that in the presence of a finite constant rate of erosion, a steady state can be reached even for a stable cosmogenic nuclide

$$
\mathrm{N}_{\mathrm{ss}} \text { (stable nuclide) }=\frac{\mathrm{P}_{0}}{\lambda+\mu \rho \varepsilon} \text {. }
$$

Equations (2) and (2') may be applicable in some cases for the Case IV in Table 1. The validity of the model (with respect to the assumption of a continuous long-term exposure with rock eroding at an uniform rate) would have to be ascertained using radionuclides of different half-lives and stable nuclides. 
In recent literature, surface exposure ages defined as the effective (or apparent) exposure age, $\mathrm{T}_{\text {eff, }}$, for a steady-state erosion model, have been obtained from accumulation of the in-situ produced nuclide in the rock compared to its production rate at the surface (Lal 1991)

$$
\begin{aligned}
\mathrm{T}_{\text {eff }} & =\frac{\mathrm{N}_{\mathrm{ss}}}{\mathrm{P}_{0}} \\
& =\frac{1}{\lambda+\mu \rho \varepsilon} .
\end{aligned}
$$

Equation (4) also leads to an estimate of the rate of erosion, $\varepsilon$, basing on the measured nuclide concentration

$$
\varepsilon=\frac{1}{\mu \rho}\left[\frac{P_{0}}{N_{\text {ss }}}-\lambda\right]=\frac{1}{\mu \rho}\left[\frac{1}{T_{\text {eff }}}-\lambda\right] .
$$

The term within brackets in Equation (5) is a nuclide-invariant quantity, proportional to the erosion rate only (Lal 1991). The validity of a steady state and uniform erosion rate can be checked by using two or more cosmogenic nuclides.

In the case of a discrete exposure of a rock, the exposure age, $\mathrm{T}$, is obtained from a measurement of $\mathrm{N}(\mathrm{T}, \lambda)$, using Equation (1), provided the nuclide mean-life is comparable to or longer than the exposure age. This involves a knowledge of $\varepsilon$, which can be estimated in favorable cases using a pair of nuclides (two radionuclides or a stable and a radioactive nuclide). In the absence of a knowledge of $\varepsilon$, a lower limit on the exposure time, $\mathrm{T}$, is given by $\mathrm{T}_{\text {eff }}$, defined in Equation (3) as

$$
\begin{aligned}
\mathrm{T}>\mathrm{T}_{\text {eff }} & =\frac{\mathrm{N}(\mathrm{T}, \lambda)}{\mathrm{P}_{0}} \\
& =\frac{1-\mathrm{e}^{-(\lambda+\mu \varepsilon) \mathrm{T}}}{\lambda+\mu \rho \varepsilon},
\end{aligned}
$$

which is a function of both $\lambda$ and $\varepsilon$. If, on any physical or chemical grounds, it can be ascertained that the total surface erosion was insignificant compared to the cosmic-ray absorption mean path (1/ $\mu$ ), i.e., $\varepsilon \mathrm{T} \ll 1 / \mu \rho$ then the exposure duration, $\mathrm{T}$, can be estimated using a stable nuclide or a radionuclide of half-life comparable to or greater than $\mathrm{T}$

$$
\mathrm{T} \simeq \mathrm{T} \approx \frac{1}{\lambda} \ln \left[1-\frac{\lambda}{\mathrm{P}_{0}} \mathrm{~N}(\mathrm{~T}, \lambda)\right]^{-1}
$$

Thus, in the case of a discrete exposure history, with or without an appreciable erosion rate, it may be possible to determine the surface exposure age, $\mathrm{T}$, which should more appropriately be called event age.

Let us now examine the difficulties one encounters in obtaining meaningful or definable cosmic-ray exposure ages, basing on Equations (3-7), the principal problem (or the culprit) being the unknown parameter, $\varepsilon$. If erosion is really negligible during the discrete/episodic surface exposure of a rock (Case III in Table 1), then one can indeed obtain the event-age basing on Equation (8). In this case the rock indeed has an identity by virtue of its shape and size, which remain essentially unchanged (length scales defined with respect to the cosmic-ray absorption mean free path distance) during its exposure to cosmic rays. Note here that if indeed $\varepsilon \simeq 0$, the rock may or may not be in steady state for a stable nuclide or a very long half-life nuclide. 
If $\varepsilon \neq 0$-and many of us in this game have often heard strong assertions in this context by experienced geologists (i.e., making a case for $\varepsilon \simeq 0$ ) to be grossly erroneous- then the question before us is, how does one define the rock exposure age? Use of Equation (3) pretends to ignore the parameter $\varepsilon$; that of Equation (4) implicitly assumes knowledge of a relationship between $\lambda$ and $\mu \rho \varepsilon$, in other words a prior knowledge of $\varepsilon$, which does not seem justifiable.

Consider now the $\lambda, \mu \rho \varepsilon$ relations for real cases, i.e., for the specific nuclides which are potentially useful in surface exposure ages, with realistic $\varepsilon$ values, for both the steady state and fixed duration exposures. For a recent discussion of the errors associated in the estimation of exposure/event ages, reference is made to Gillespie and Bierman (1995) and Macchiaroli (1995). The radionuclides considered in the present analyses are the spallogenic nuclides ${ }^{1}:{ }^{39} \mathrm{Ar}$ (half-life, $\left.\mathrm{T}_{1 / 2}=275 \mathrm{yr}\right),{ }^{14} \mathrm{C}\left(\mathrm{T}_{1 / 2}\right.$ $=5730 \mathrm{yr}),{ }^{36} \mathrm{Cl}\left(\mathrm{T}_{1 / 2}=0.3 \times 10^{6} \mathrm{yr}\right),{ }^{26} \mathrm{Al}\left(\mathrm{T}_{1 / 2}=0.7 \times 10^{6} \mathrm{yr}\right)$ and ${ }^{10} \mathrm{Be}\left(\mathrm{T}_{1 / 2}=1.5 \times 10^{6} \mathrm{yr}\right)$. Figure 1 plots the expected accumulation of the selected nuclides in the rock at its surface, $z=0$, as a function of time, for initial zero concentrations, for two assumed erosion rates, $10^{-3}$ and $10^{-5} \mathrm{~cm} \mathrm{yr}^{-1}$. The surface production rate, $P_{0}$, in each case is assumed to be 1 atom $\mathrm{g} \mathrm{yr}^{-1}$. Other cases where the depth dependence departs from the simple exponential will be considered separately. The curves in Figure 1 clearly demonstrate the sensitivity of the effective exposure age to erosion. Note that $T_{\text {eff }}=N$, since $\mathrm{P}_{0}$ has been set $=1$. When $\varepsilon=10^{-3} \mathrm{~cm} \mathrm{yr}^{-1}$, the normalized concentrations of ${ }^{36} \mathrm{Cl},{ }^{26} \mathrm{Al}$, ${ }^{10} \mathrm{Be}$ and a stable nuclide are all nearly the same, $\sim 5 \times 10^{4}$. For the case $\varepsilon \sim 10^{-5} \mathrm{~cm} \mathrm{yr}^{-1}$, a rather low rate of erosion, observed to date only in the polar regions (Nishiizumi et al. 1991, 1993), the buildup of longlived and stable nuclei is essentially linear for exposure durations of $<10^{5} \mathrm{yr}$, for ${ }^{36} \mathrm{Cl},{ }^{26} \mathrm{Al}$ and ${ }^{10} \mathrm{Be}$. The effect of erosion becomes gradually more important as one moves to nuclides of higher $\tau$-values, as can be seen clearly in Figure 1 . With $\varepsilon=10^{-5} \mathrm{~cm} \mathrm{yr}^{-1}$, the steady-state value for ${ }^{26} \mathrm{Al}$ and longer lived nuclides is reached only for surface exposure ages exceeding $10^{6} \mathrm{yr}$; for ${ }^{36} \mathrm{Cl}\left(\tau=4.3 \times 10^{5} \mathrm{yr}\right.$ ).

Figure 2 plots the expected log of nuclide concentrations at the surface, as a function of depth for different erosion rates, for the case of steady state with uniform erosion rate (again, $\mathrm{P}_{0}$ has been set to 1 atom $\mathrm{g}^{-1} \mathrm{yr}^{-1}$ ). The depth dependence of concentrations is an exponential, as theoretically expected (Lal 1991), and is given by the five straight lines. Any point on these lines gives the nuclide concentration which the rock matrix would attain when a deep-seated rock (implying zero initial concentrations at large depths) moves up to that depth. The same figure also shows the time it takes for a layer (marked by intersecting curves) to outcrop to the surface, for different erosion rates. This figure is very instructive, since it graphically shows the time required for the nuclide concentrations at its present surface to reach its present value from different depths, for different erosion rates.

Several interesting features of the buildup of nuclide concentration can be deduced from Figures 1 and 2, which I have briefly alluded to earlier (Lal 1991). I would like to point out here one very interesting feature of the buildup, which can be used to put constraints on erosional models used. This point revolves around the central assumption of a continuous and uniform erosion. In natural situations, it is known that often large blocks can be removed due to floods/landslides, all related to rock fracture along certain planes. The in-situ cosmogenic nuclides can be used to check on this. As discussed earlier, Figure 1 shows the expected exponential depth-dependence of $\mathrm{N}$. If a surface layer is removed, say of a thickness $\sim 1$ mean cosmic-ray-absorption distance, $(1 / \mu \rho) \mathrm{cm}$, then the nuclide concentration in this layer, now at the surface, would be lower than expected, by a factor of "e". Consequently, the apparent surface exposure age would be lower, corresponding to an apparent

\footnotetext{
${ }^{1}$ Note that in all the calculations presented here, it is assumed that the nuclide production rate decreases exponentially with depth, z, with a mean absorption distance of $160 \mathrm{~g} \mathrm{~cm}^{-2}$ ( $\mathrm{Lal} 1991$ ). In the case of ${ }^{36} \mathrm{Cl}$, its production by thermal neutrons is often important. Its production rate shows a broad transition at ca. $40-100 \mathrm{~g} \mathrm{~cm}^{-2}$ (Dep et al. 1994).
} 


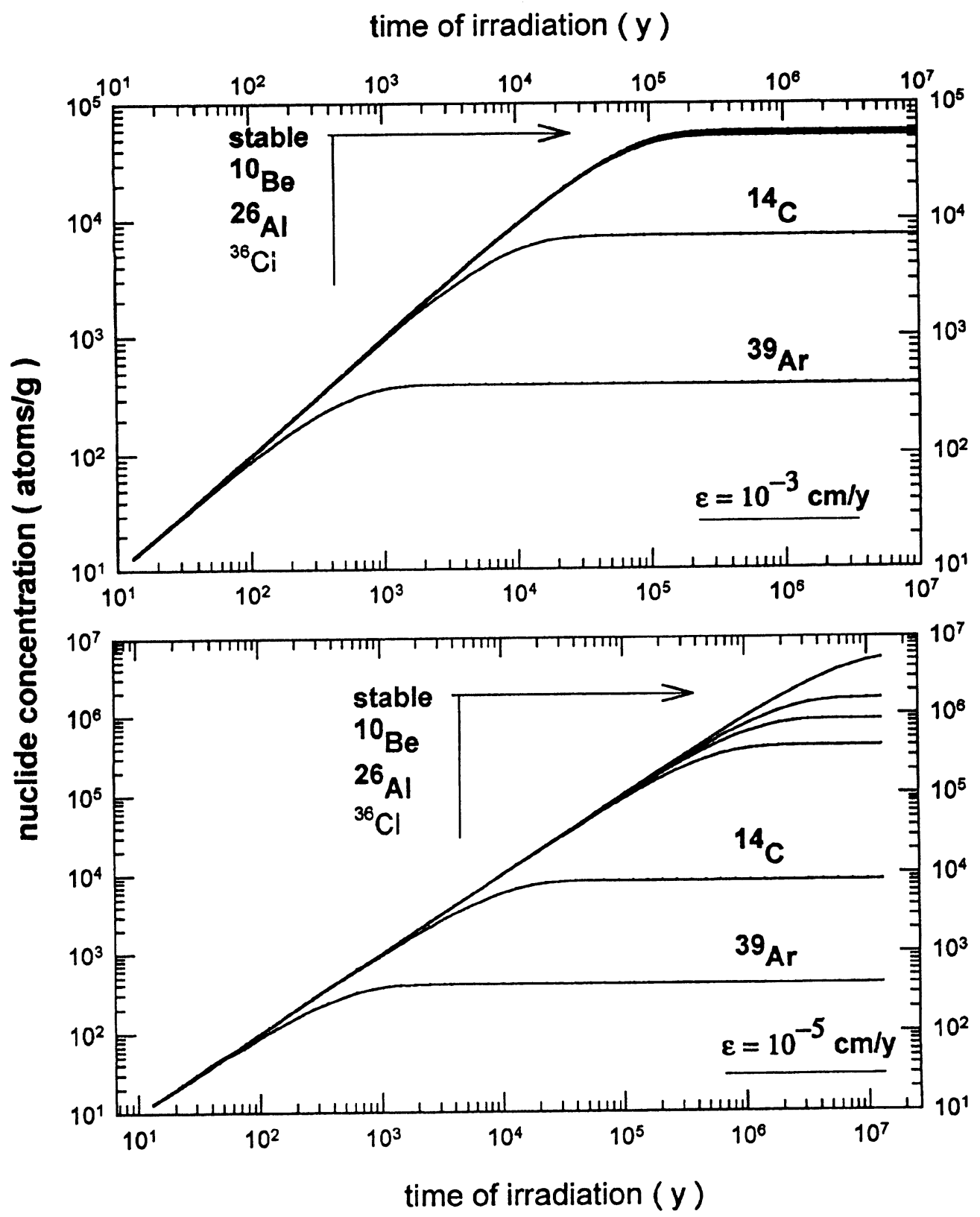

Fig. 1. Expected nuclide concentrations (atom $\mathrm{g}^{-1}$ ) in the surface of a rock of density $2.7 \mathrm{~g} \mathrm{~cm}^{-3}$, exposed for different periods of time, for five radionuclides and one stable nuclide. The surface production rate, $P_{0}$, is assumed to be 1 atom $\mathrm{g}^{-1} \mathrm{y}^{-1}$.

higher erosion rate. This effect is not independent of the nuclide half-life. The shorter the half-life, the greater the shift would be in the apparent erosion rate. The longer-lived and stable nuclides would be subjected to a much smaller shift. The reason for this is that $T_{\text {eff }}$ is smaller for a shorterlived nuclide, and any lowering of the surface value due to removal of a slab causes greater overes- 
timation of the rate of erosion for a shorter-lived nuclide (Eq. 5). One can therefore constrain exposure histories easily by studying two or more nuclides of different half-lives (Lal 1991). In the case of steady-state erosion, the invariant quantity for all in-situ nuclides is: $P_{0} / N-\lambda$; however, for a discrete exposure of a previously shielded rock, it is not possible to define an invariant quantity, but a check can nevertheless be made for the validity of the exposure model used by studying several insitu produced nuclides.

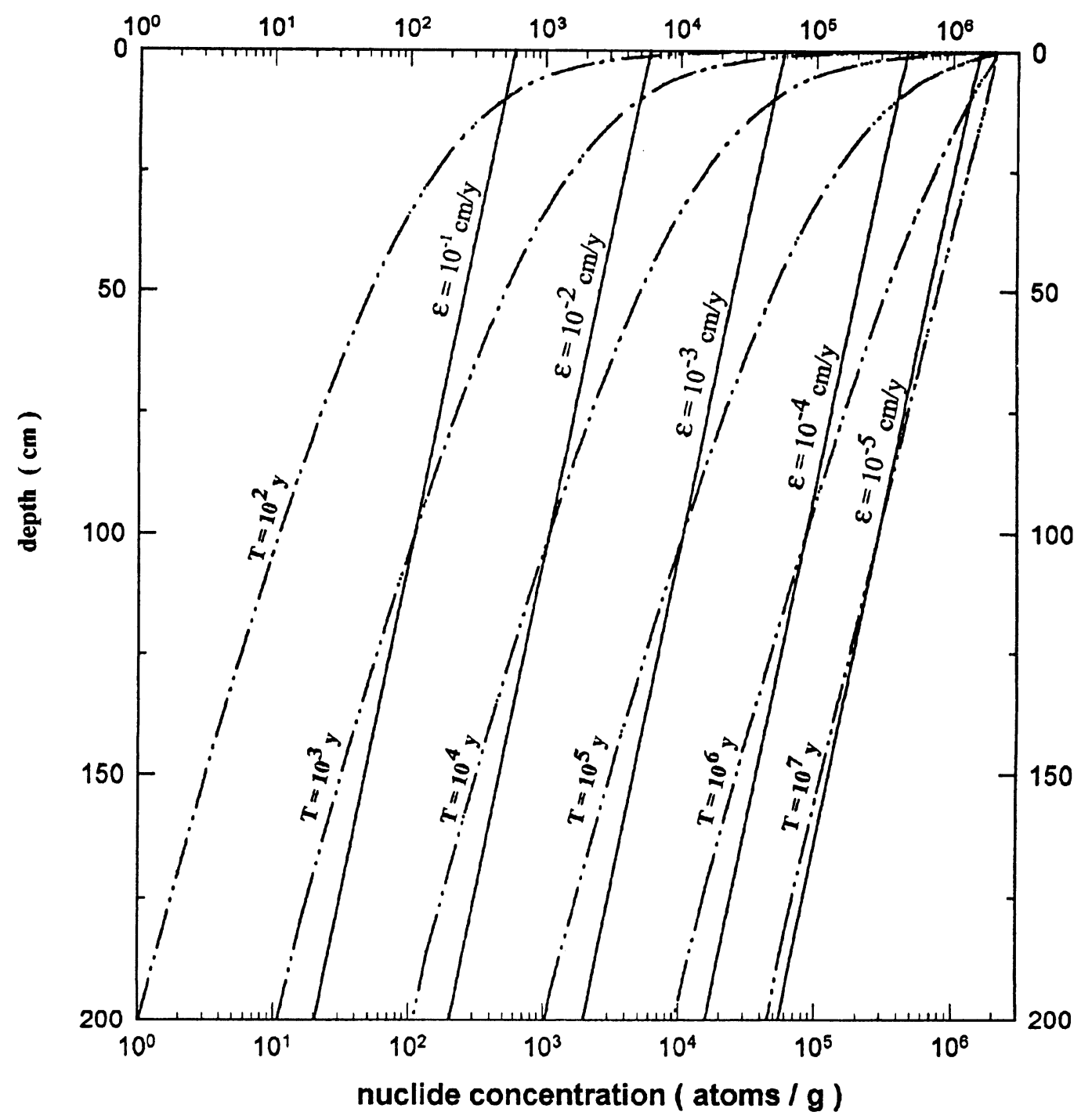

Fig. 2. The figure shows graphically how nuclide concentrations grow in a rock for the case of steady-state cosmicray irradiation. The (parallel) solid lines give the nuclide concentrations attained at different depths as a given stratum moves up due to erosion, for $\varepsilon=10^{-5}-10^{-1} \mathrm{~cm} \mathrm{yr}^{-1}$. The intersection between the straight lines and the dotted iso-time curves for $10^{2}-10^{7} \mathrm{yr}$ give the time taken for a surface at that depth to outcrop to surface with that erosion rate; values for other depths and erosion rates can be estimated by an interpolation. 
From the preceding it becomes clear that for both long-term/steady-state erosion or short-term buildup in a shielded rock, the effective exposure age obtained, $\mathrm{T}_{\text {eff }}$, is not an unique quantity but is a function of nuclide half-life and erosion rate. Thus, quoting $T_{\text {eff }}$ as the exposure age without further qualification would be incorrect. One should therefore decide on an agreed mode of presentation of results which even a non-specialist can use as a numeric value whose meaning is well understood, even by a non-practitioner. I propose that one should totally separate the question of the nuclide halflife from the surface exposure age of a rock, meaning that any quantity quoted as the exposure age should be free from the physical influence of $\lambda$, the half-life of the spallogenic nuclide measured. For the case of steady-state erosion, this is easily done by first deriving $\varepsilon$ from observations of cosmogenic nuclides, which is the principal quantity which the nuclear method provides for a continuously eroding rock. Having done this, one should then deduce the cosmic-ray surface exposure age for a stable spallogenic nuclide, which is the value of $T_{\text {eff }}$ (Eq. 3) for a stable nuclide (i.e., for the case, $\lambda=0$ ). The desired quantity $\mathrm{T}_{\text {eff }}($ stable) is given by

$$
\mathrm{T}_{\text {eff }}(\text { stable })=\left(\frac{\mathrm{N}_{\mathrm{ss}}}{\mathrm{P}_{0}}\right) \text { stable }=\frac{1}{\mu \rho \varepsilon}=\mathrm{T}_{\text {ero }}
$$

if a stable nuclide was used, and this is the estimated surface exposure age, controlled by erosion alone, $\mathrm{T}_{\text {ero }}$ As a general note, the choice of a stable nuclide for defining exposure age is advantageous: 1) first, it is less sensitive to any departures from continuous and uniform erosion (Lal 1991); and 2) the accumulation of the nuclide is linear with exposure duration (Fig. 1), controlled by erosion only. Note that this simplification is possible since the value of the cosmic-ray absorption coefficient, $\mu$, is the same for all spallogenic nuclides (Lal 1988, 1991).

In light of the above, then, since the cosmogenic nuclides can at best be expected to provide only the erosion rates, one should study them to estimate the erosion rate. If this can be done adequately, then (ideal condition: $\lambda \sim \mu \rho \varepsilon$ ) in cases where a steady-state erosional model is valid, one should quote $(1 / \mu \rho \varepsilon)$ as the erosion-controlled surface exposure age, $T_{\text {ero }}=T_{\text {eff }}$ (stable). This is the time in which the rock erodes to a depth equal to the cosmic-ray absorption mean free path, $160 \mathrm{~g} \mathrm{~cm}^{-2}$ (Eq. 9).

Table 2 shows the data for ten Antarctic rocks, selecting a few samples from each of the sites, ALH, BW and TAC, studied by Nishiizumi et al. (1991) for ${ }^{10} \mathrm{Be}$ and ${ }^{26} \mathrm{Al}$ concentrations. In Table 3, the conventional apparent ages, $T_{\text {eff }}$, and the erosion rates based on ${ }^{10} \mathrm{Be}$ and ${ }^{26} \mathrm{Al}$ are given separately, along with the $\mathrm{T}_{\text {ero }}$ ages. The general pattern is as expected: $\mathrm{T}_{\text {ero }}>\mathrm{T}_{\text {eff }}\left({ }^{10} \mathrm{Be}\right)>\mathrm{T}_{\text {eff }}\left({ }^{26} \mathrm{Al}\right)$. And when $\varepsilon$ is large, the differences between these age estimates decrease.

The case of an episodic event (Case III in Table 1) has already been discussed (Eqs. 6-8). In this case, the quantity of interest is the exposure age, $\mathrm{T}$, which can be determined directly using two (or more) suitable nuclides. If this is feasible, then $T$ should be cited as an "event age". But in the absence of any knowledge of $\varepsilon$, a lower limit to $T$ should be given by the effective cosmic-ray exposure age, $\mathrm{T}_{\text {eff }}$ (Eq. 6).

Finally, let us consider cases of cosmogenic in-situ nuclides that do not obey the exponential depth dependence in production. Specific cases are ${ }^{36} \mathrm{Cl}$ production by slow neutron capture in the upper rock strata at depths $<\sim 150 \mathrm{~g} \mathrm{~cm}^{-2}$ (Dep et al. 1994), and nuclides that can be produced in muon capture reactions, at underground depths exceeding a few hundred $\mathrm{g} \mathrm{cm}^{-2}$ below sea level (Lal 1987, 1988). The production of ${ }^{36} \mathrm{Cl}$ in limestone is an example of this (Stone et al. 1994) and arises from the changeover in production mechanism, from the fast nucleonic component to muons, whereby the mean absorption distance becomes depth-variant. Note that irrespective of the nuclide production mechanism, the cosmic-ray exposure age, $\mathrm{T}_{\text {ero }}$, could be estimated in a similar manner as dis- 

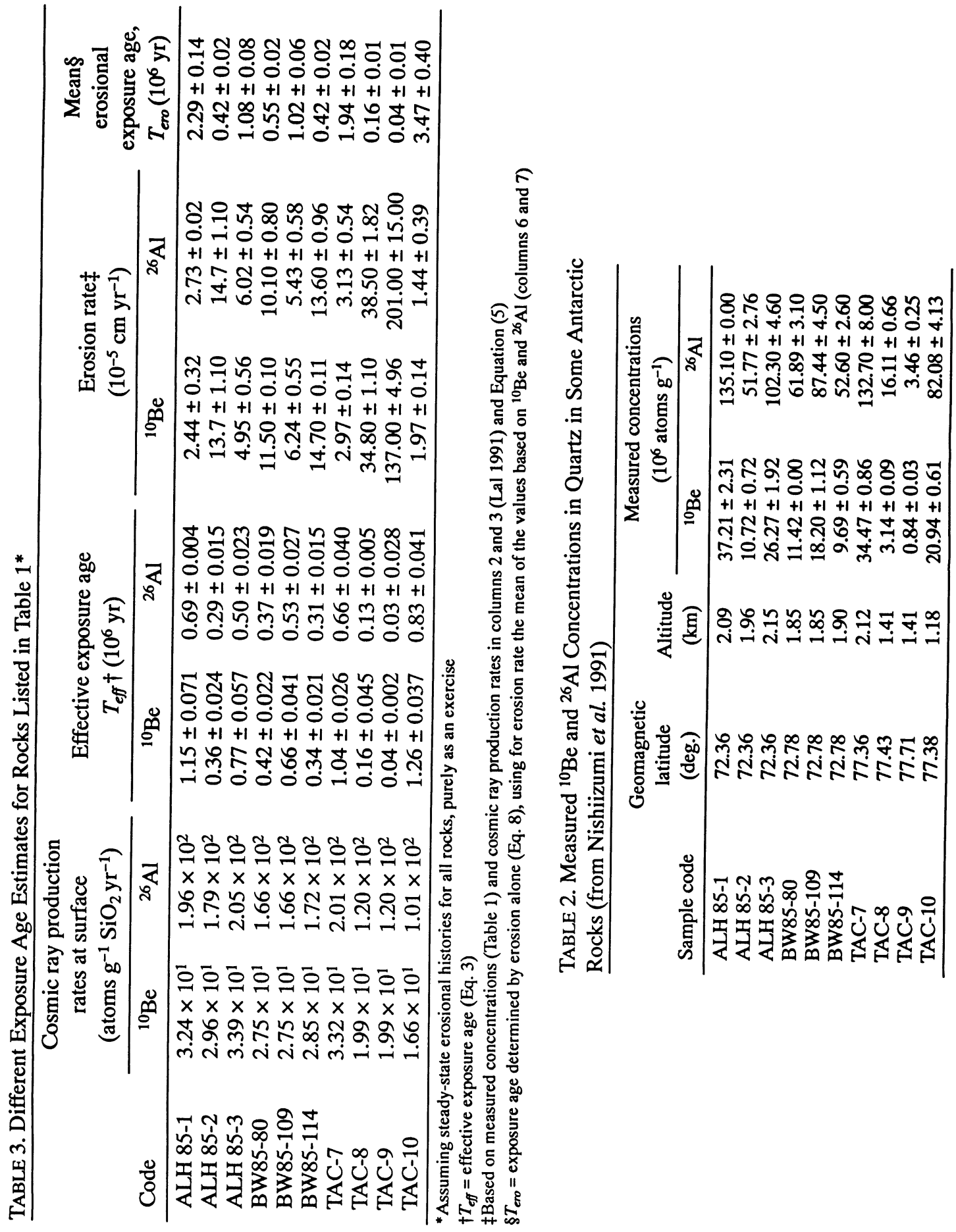
cussed above, i.e., first determine the erosion rate and then present the "erosion-controlled" surface exposure age for the case of a stable spallogenic nuclide, for which the mean cosmic-ray absorption distance is $160 \mathrm{~g} \mathrm{~cm}^{-2}$.

\section{ACKNOWLEDGMENTS}

I wish to thank A. J. T. Jull and J. C. Gosse for their valuable discussions and suggestions.

\section{REFERENCES}

Bhattacharya, S. K., Goswami, J. N. and Lal, D. 1973 Semi-empirical rates of formation of cosmic ray tracks in spherical objects exposed in space: Pre-atmospheric and post-atmospheric depth profiles. Journal of Geophysical Research 78: 8356-8363.

Bhattacharya, S. K., Imamura, M., Sinha, N. and Bhandari, N. 1980 Depth and size dependence of ${ }^{53} \mathrm{Mn}$ activity in chondrites. Earth and Planetary Science Letters 51: 45-57.

Bierman, P. R., Gillespie, A. R. and Caffee, M. W. 1995 Cosmogenic ages for earthquake recurrence, intervals and debris flow fan deposition, Owens Valley, California. Science 270: 447-450.

Brook, E. J., Kurz, M. D., Ackert, R. P., Denton, G. H. and Brown, E. T. 1993 Chronology of Taylor Glacier advances in Arena Valley, Antarctica, using in situ cosmogenic ${ }^{3} \mathrm{He}$ and ${ }^{10} \mathrm{Be}$. Quaternary Research 39: 11-23.

Brown, E. T., Edmond, J. M., Raisbeck, G. M., Yiou, F. and Kurz, M.D. 1991 Examination of surface exposure ages of Antarctic moraines using in situ ${ }^{10} \mathrm{Be}$ and ${ }^{26} \mathrm{Al}$. Geochimica et Cosmochimica Acta 55: 2269-2283.

Cerling, T. E. and Craig, H. 1994a Geomorphology and in-situ cosmogenic isotopes. Annual Review of Earth and Planetary Sciences 22: 273-277. $1994 \mathrm{~b}$ Cosmogenic ${ }^{3} \mathrm{He}$ production rates from $39^{\circ}$ to $46^{\circ} \mathrm{N}$ latitude, Western USA and France. Geochimica et Cosmochimica Acta 58: 249-255.

Dep, L., Elmore, D., Fabryka-Martin, J. and Reedy, R. C. 1994 Production rate systematics of in-situ produced cosmogenic nuclides in terrestrial rocks: Monte Carlo approach of investigating ${ }^{35} \mathrm{Cl}(\mathrm{n}, \gamma)^{36} \mathrm{Cl}$. Nuclear Instruments and Methods in Physics Research B92: 321-325.

Geiss, J., Oeschger, H. and Signer, P. 1960 Radiation ages of chondrites. Zeitschrift für Naturforschung 15A: 1016-1017.

Gillespie, A. R. and Bierman, P. R. 1995 Precision of terrestrial exposure ages and erosion rates estimated from analysis of cosmogenic isotopes produced in situ. Journal of Geophysical Research 100(B12): $24,637-24,649$.

Gosse, J. C., Klein, J., Evenson, E. B., Lawn, B. and Middleton, R. 1995 Beryllium-10 dating of the duration and retreat of the last Pinedale Glacial sequence. Science 268: 1329-1333.

Kurz, M. D., Colodner, D., Trull, T. W., Moore, R. B. and O'Brien, K. 1990 Cosmic ray exposure dating with in situ produced cosmogenic ${ }^{3} \mathrm{He}$ : Results from young Hawaiian lava flows. Earth and Planetary Science Letters 97: 177-189.

Lal, D. 1972 Hard rock cosmic ray archaeology. Space Science Reviews 14: 3-102.

1987 Production of ${ }^{3} \mathrm{He}$ in terrestrial rocks. Chemical Geology 66: 89-98.

1988 In situ-produced cosmogenic isotopes in terrestrial rocks. Annual Review of Earth and Planetary Science 16: 355-388.

1991 Cosmic ray tagging of erosion surfaces: in situ nuclide production rates and erosion models. Earth and Planetary Science Letters 104: 424-439.

Macchiaroli, P. E. 1995 Revolving aspects of past galciations by dating exposed rock surfaces using ${ }^{26} \mathrm{Al}$ and ${ }^{10} \mathrm{Be}$ produced in situ: Wright Valley, Southern Victoria Land, Antarctica and the southeasternmost ridge of the Appalachian Mountains. Ph.D. dissertation, University of Pennsylvania.

Marti, K. and Graf, T. 1992 Cosmic ray exposure history of ordinary chondrites. Annual Review of Earth and Planetary Science 20: 221-243.

Nishiizumi, K., Lal, D., Klein, J., Middleton, R. and Arnold, J. R. 1986 Production of ${ }^{10} \mathrm{Be}$ and ${ }^{26} \mathrm{Al}$ by cosmic ray in terrestrial quartz in situ and implications for erosion rates. Nature 319: 134-136.

Nishiizumi, K., Kohl, C. P., Arnold, J. R., Dorn, R., Klein, J., Fink, D., Middleton, R. and Lal, D. 1993 Role of in-situ cosmogenic nuclides ${ }^{10} \mathrm{Be}$ and ${ }^{26} \mathrm{Al}$ in the study of diverse geomorphic processes. Earth Surface Processes and Landforms 18: 407-425.

Nishiizumi, K., Kohl, C. P., Arnold, J. R., Klein, J., Fink, D. and Middleton, R. 1991 Cosmic ray produced ${ }^{10} \mathrm{Be}$ and ${ }^{26} \mathrm{Al}$ in Antarctic rocks: exposure and erosion history. Earth and Planetary Science Letters 104: 440-454.

Phillips, F. M., Leavy, B. D., Jannik, N. O., Elmore, D. and Kubik, P. W. 1986 The accumulation of cosmogenic chlorine-36 in rocks: A method for surface exposure dating. Science 231: 41-43.

Reedy, R. C. 1981 Cosmic-ray-produced stable nuclides: various production rates and their implications. Proceedings of Lunar and Planetary Science 12B: 18091823.

Stone, J., Allan, G. L., Tifield, L. K., Evans, J. M. and Chivas, A. R. 1994 Limestone erosion measurements with cosmogenic chlorine-36 in calcite; preliminary results from Australia. Nuclear Instruments and Methods in Physics Research B92: 311-316. 